Supplement of Atmos. Chem. Phys., 20, 2667-2693, 2020

https://doi.org/10.5194/acp-20-2667-2020-supplement

(C) Author(s) 2020. This work is distributed under

the Creative Commons Attribution 4.0 License.

(c) (i)

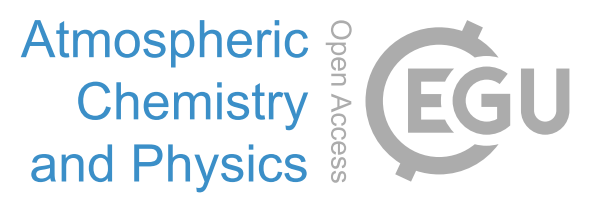

Supplement of

\title{
MICS-Asia III: overview of model intercomparison and evaluation of acid deposition over Asia
}

Syuichi Itahashi et al.

Correspondence to: Syuichi Itahashi (isyuichi@criepi.denken.or.jp)

The copyright of individual parts of the supplement might differ from the CC BY 4.0 License. 

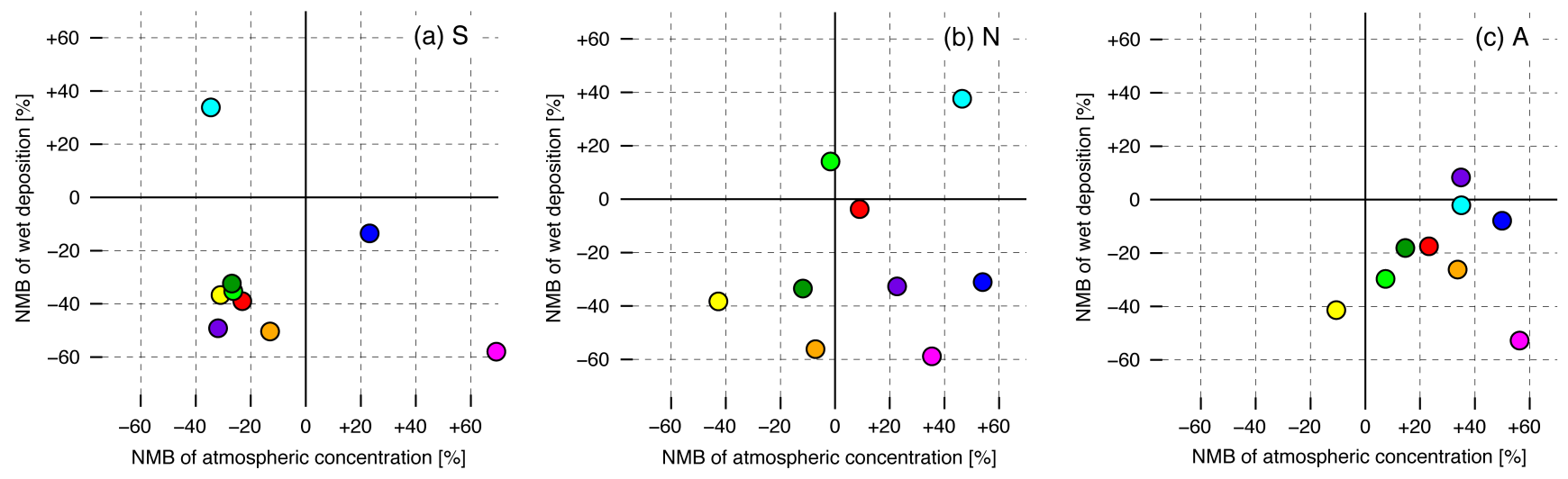

\begin{tabular}{llllllllll} 
M1 & M2 & M/4 & M5 & M6 & M11 & M12 & M13 & M14 \\
\hline & 0 & 0 & 0 & 0 & 0 & 0 & 0 & 0
\end{tabular}

Figure S1. Correspondence between the NMB of atmospheric concentration and the NMB of wet deposition for (a) S, (b) N, and (c) A. 

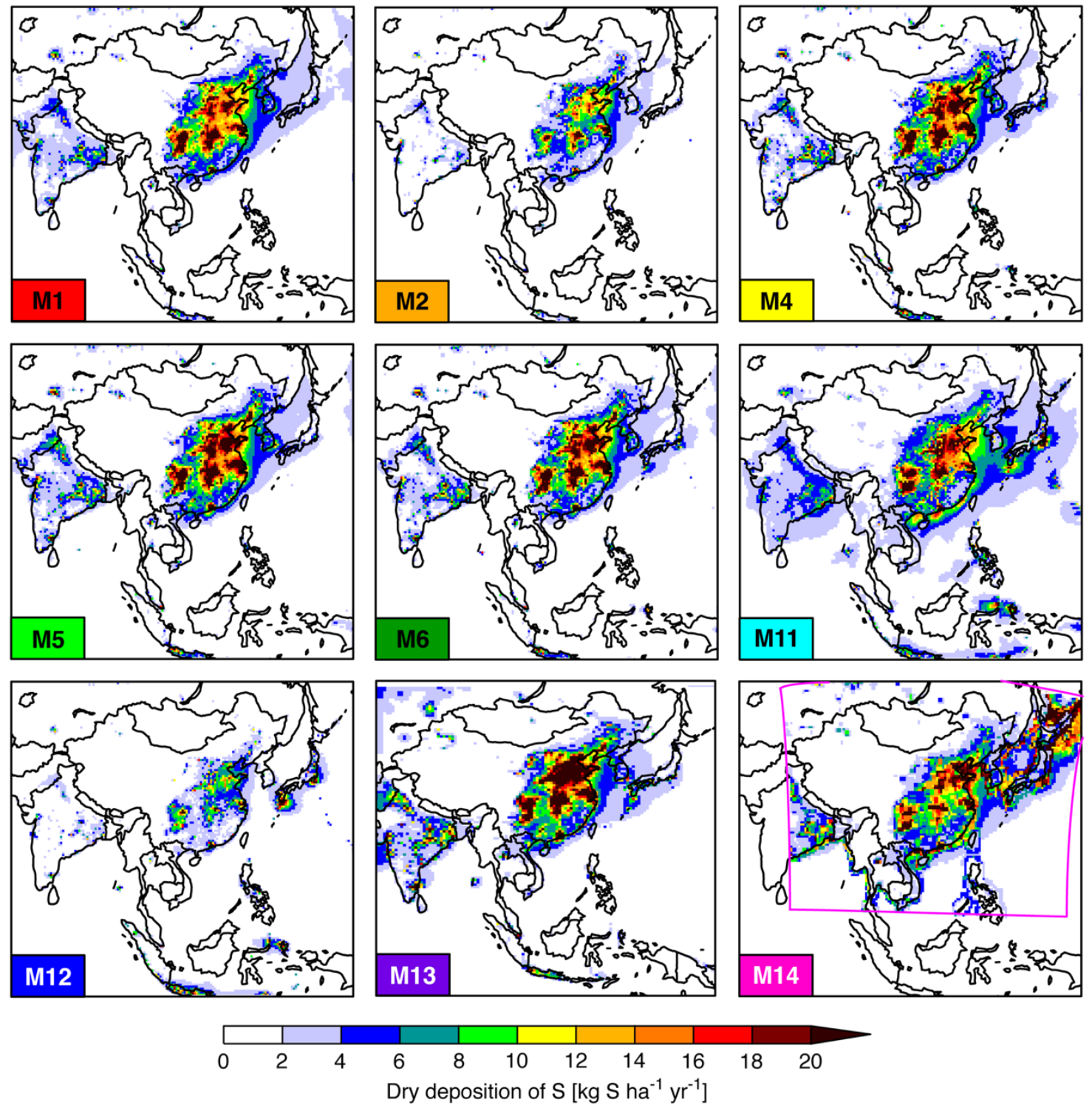

Figure S2. Spatial distributions of the annual accumulated dry deposition of S. 

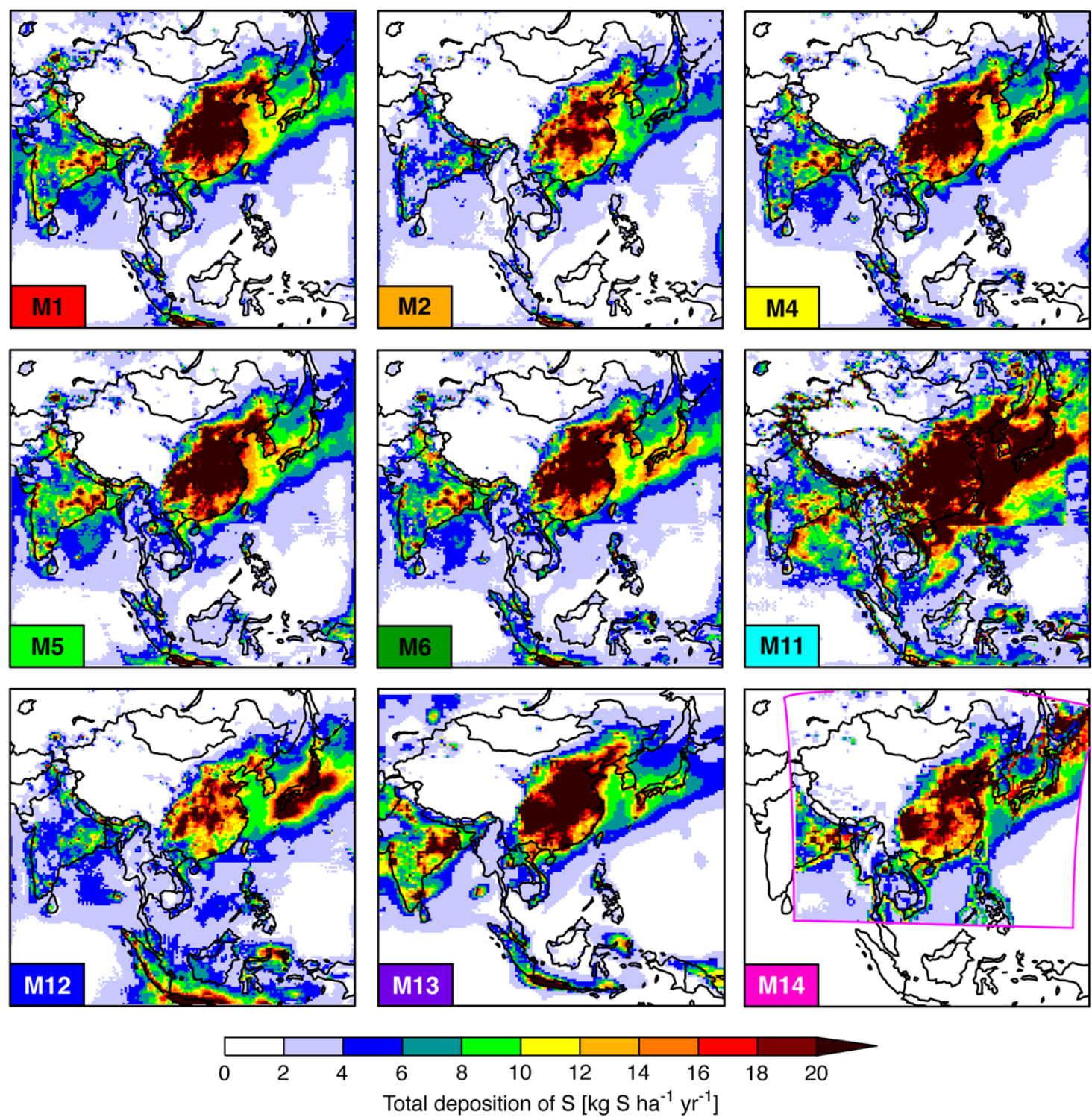

Figure S3. Spatial distributions of the annual accumulated total deposition of S. 

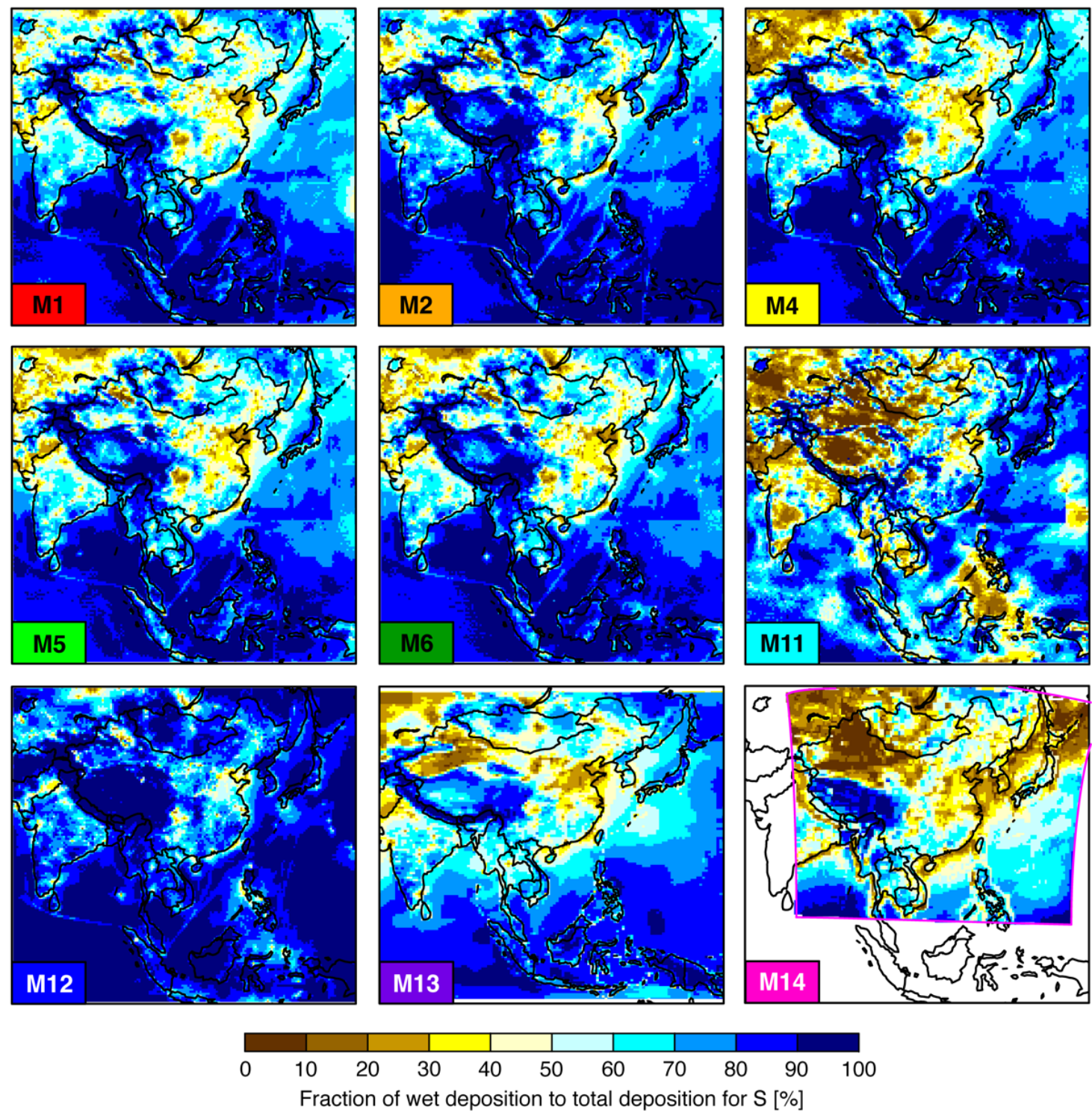

Figure S4. Spatial distributions of the proportion of the wet deposition of $S$ to the total deposition of $S$ on the annual mean. 

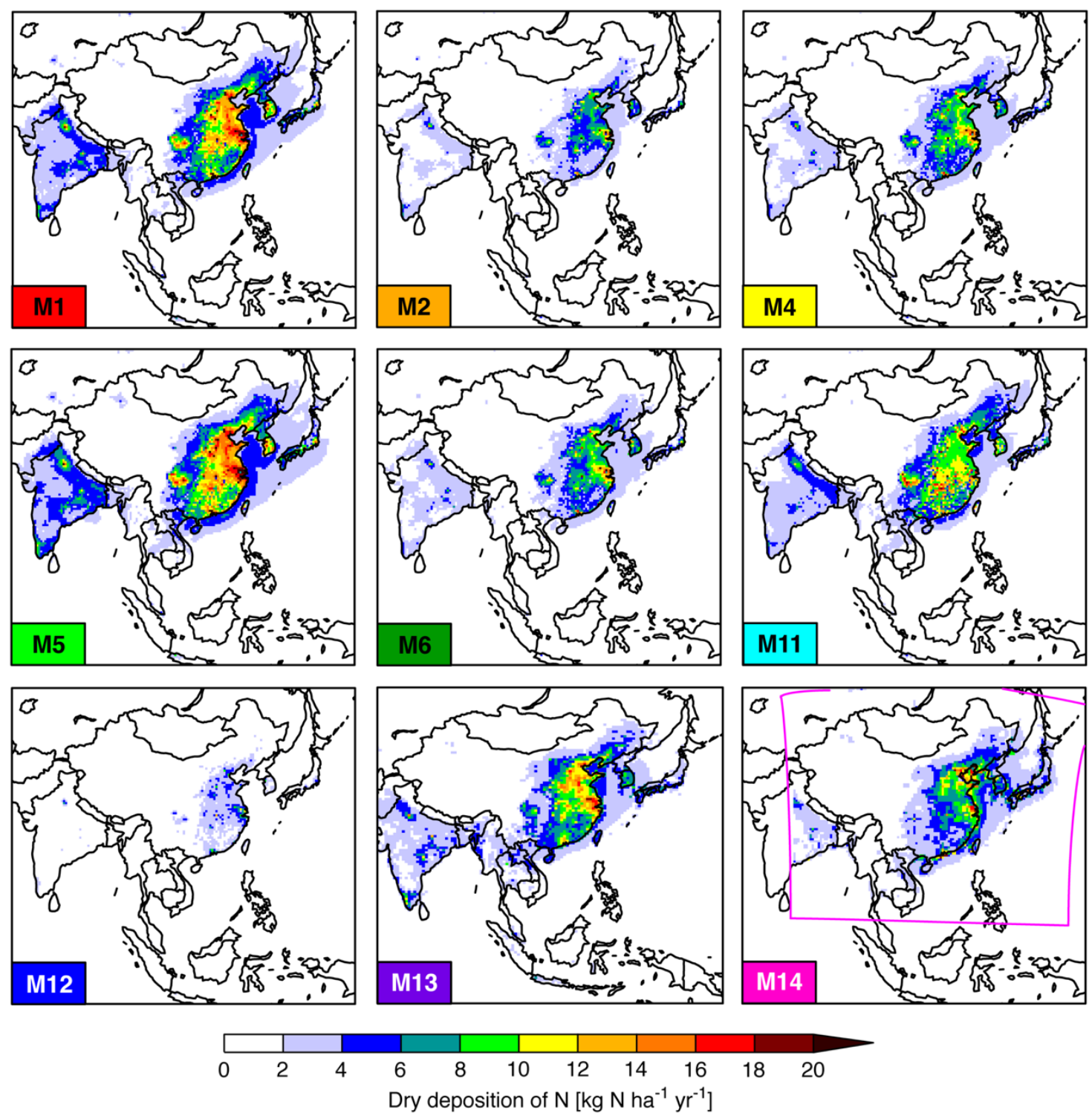

Figure S5. Spatial distributions of the annual accumulated dry deposition of $\mathbf{N}$. 

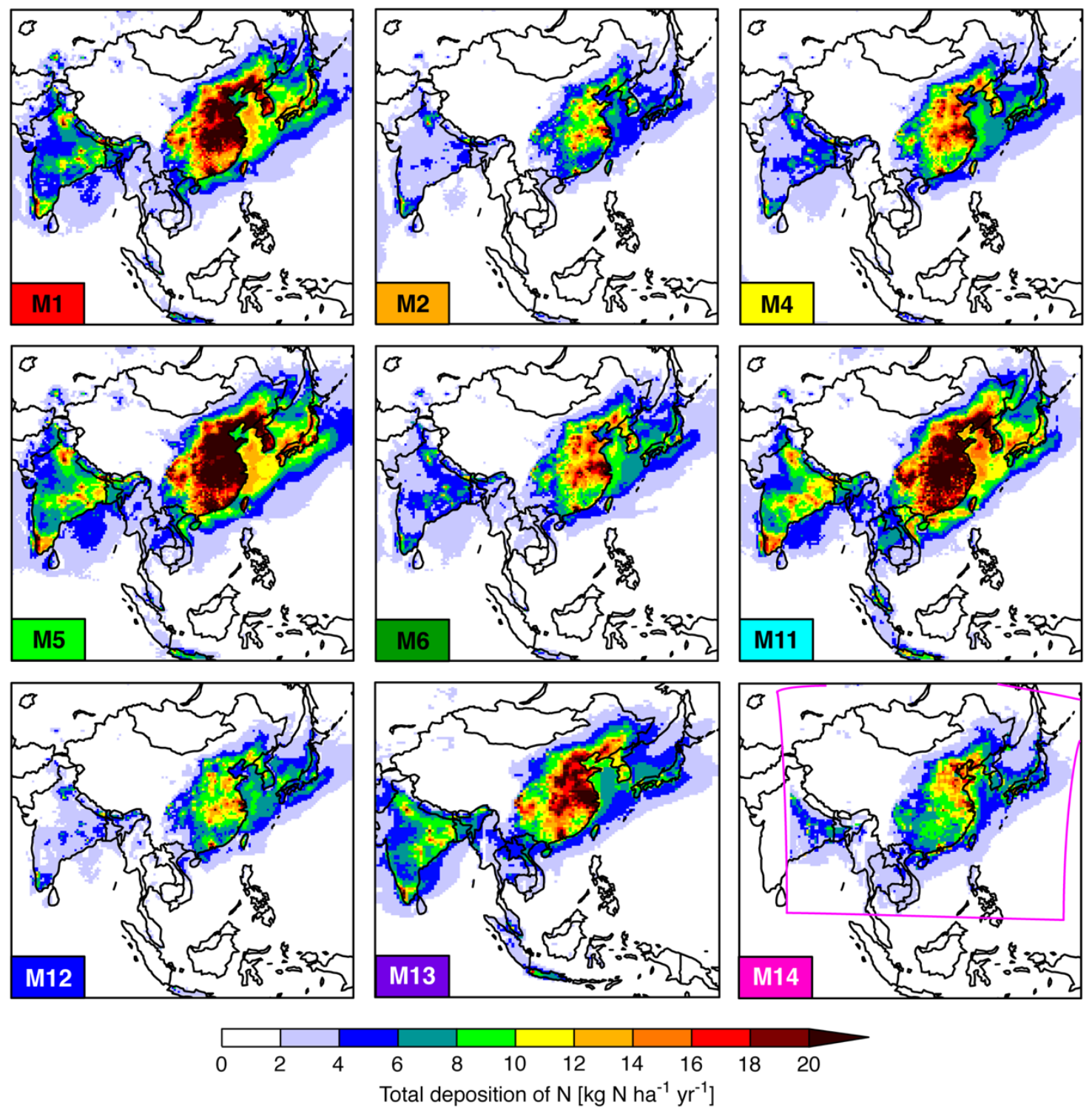

Figure S6. Spatial distributions of the annual accumulated total deposition of $\mathbf{N}$. 

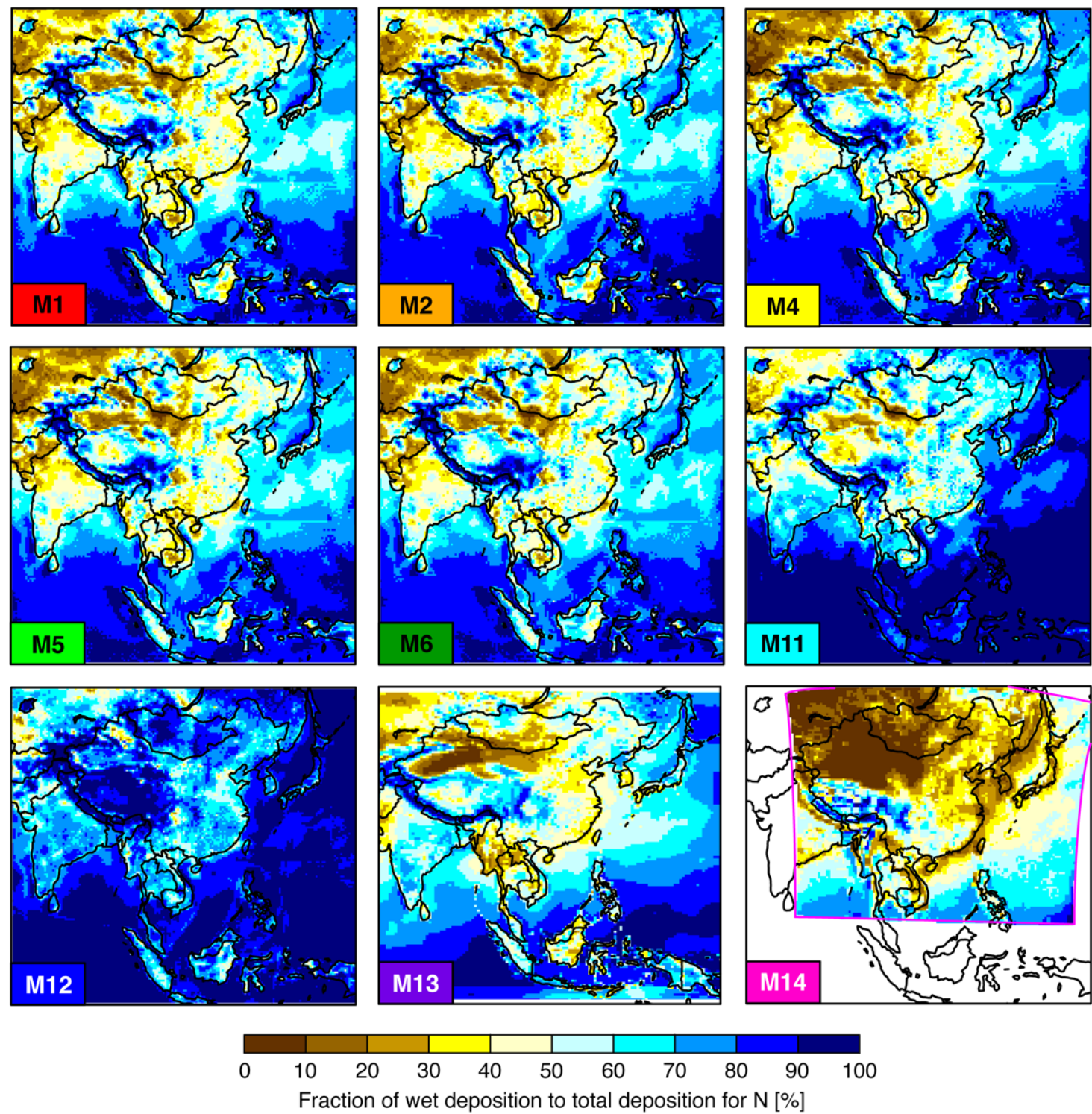

Figure S7. Spatial distributions of the proportion of the wet deposition of $\mathrm{N}$ to the total deposition of $\mathrm{N}$ on the annual mean. 

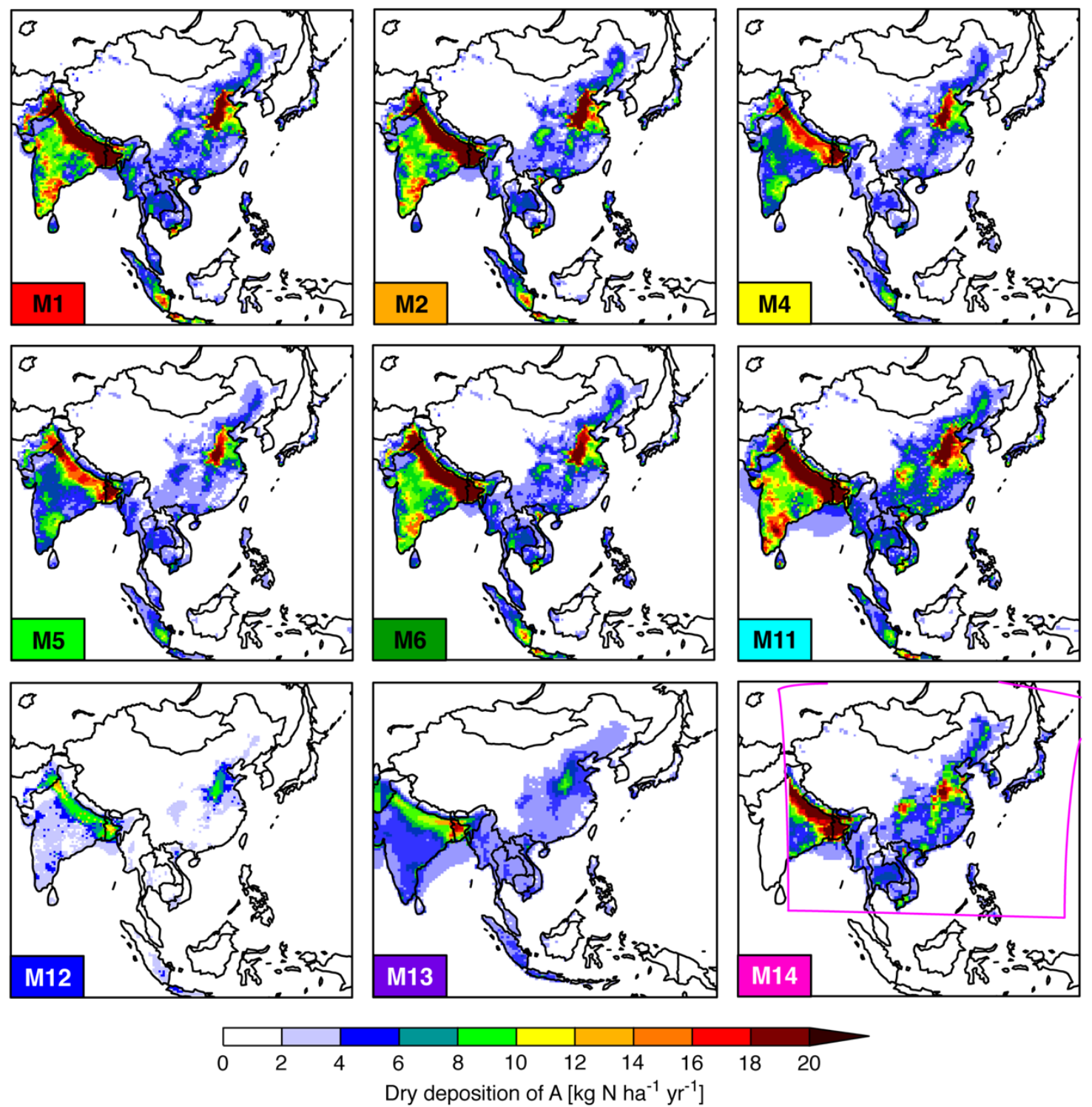

Figure S8. Spatial distributions of the annual accumulated dry deposition of A. 

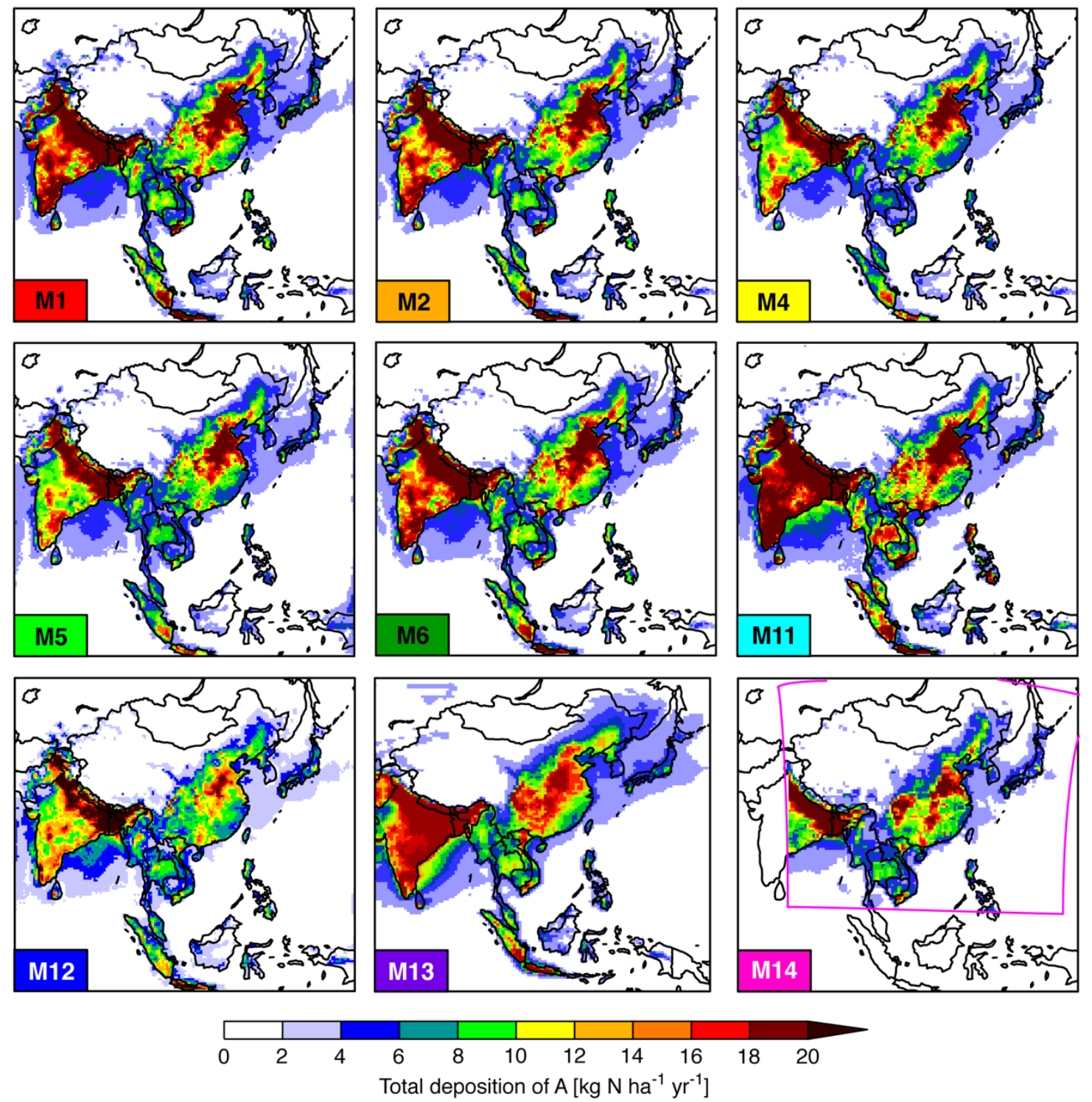

Figure S9. Spatial distributions of the annual accumulated total deposition of A. 

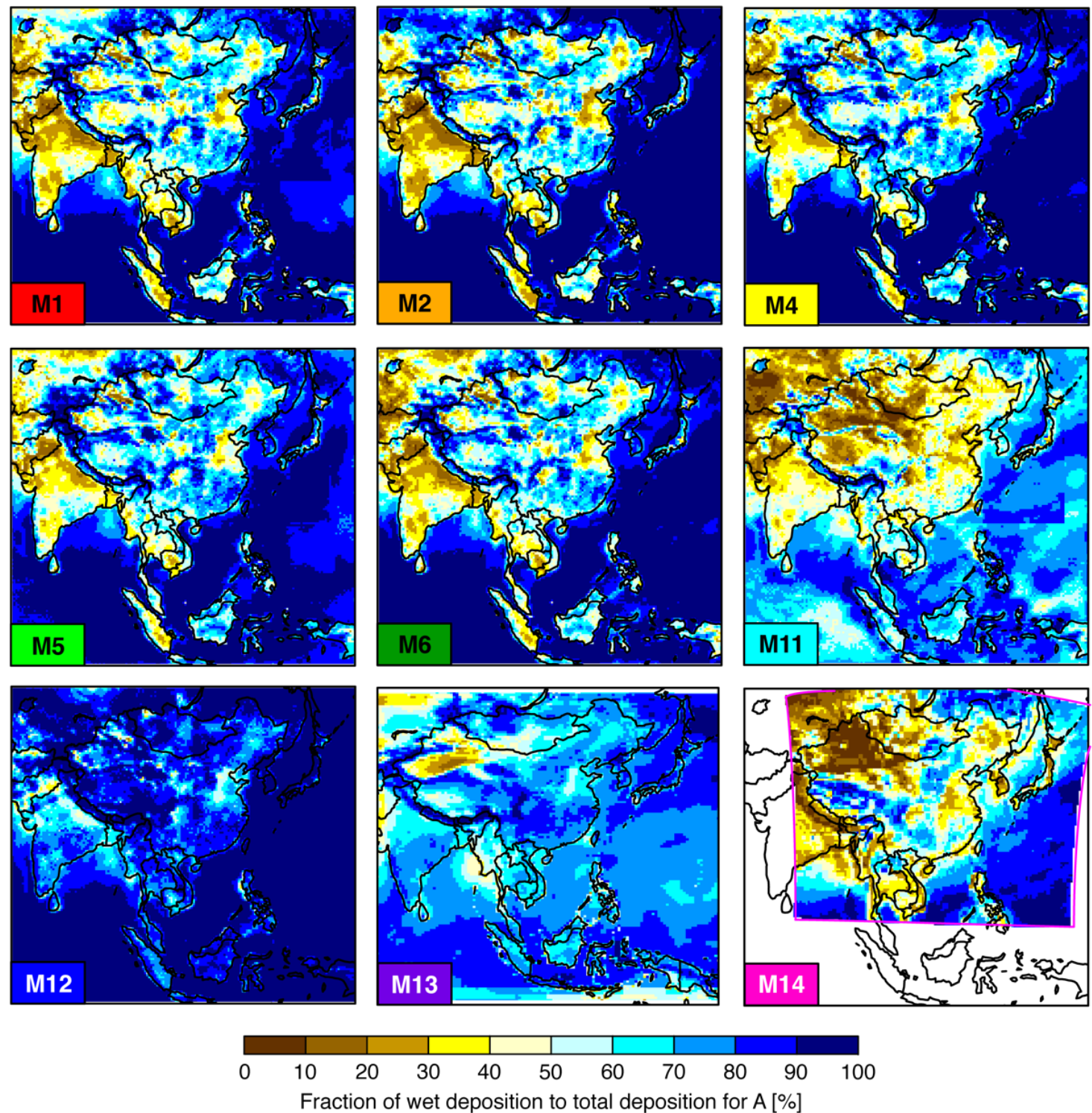

Figure S10. Spatial distributions of the proportion of the wet deposition of A to the total deposition of A on the annual mean. 
(a) Dry deposition of $\mathrm{S}$

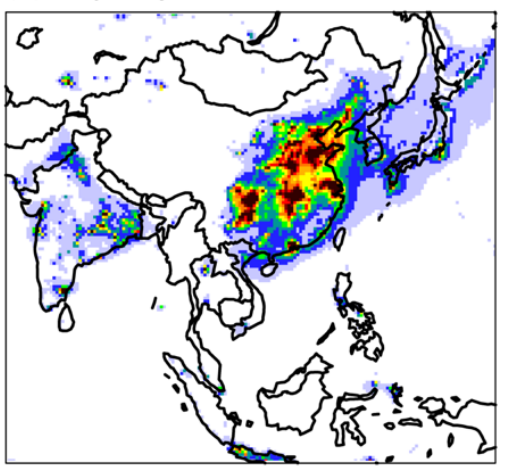

(b) Dry deposition of $\mathrm{N}$

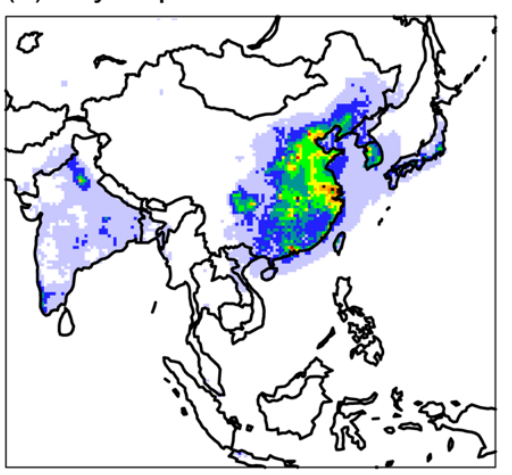

(c) Dry deposition of $A$

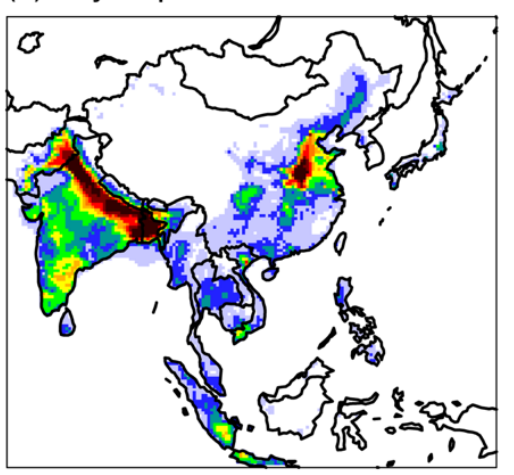

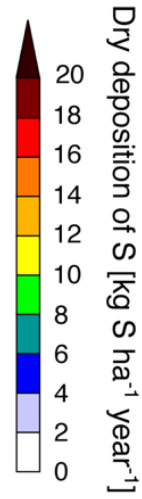

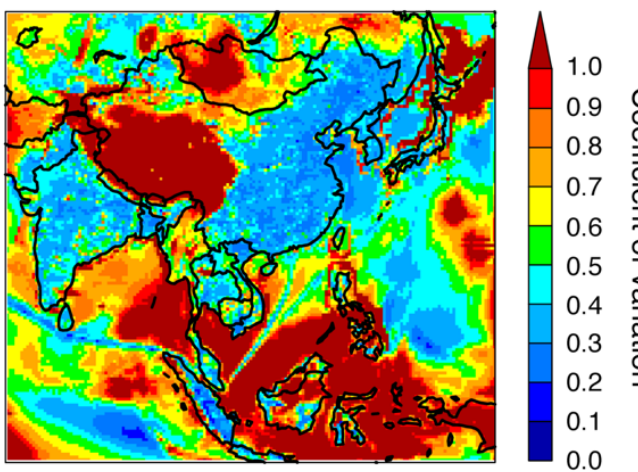

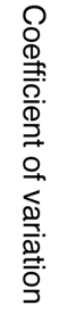
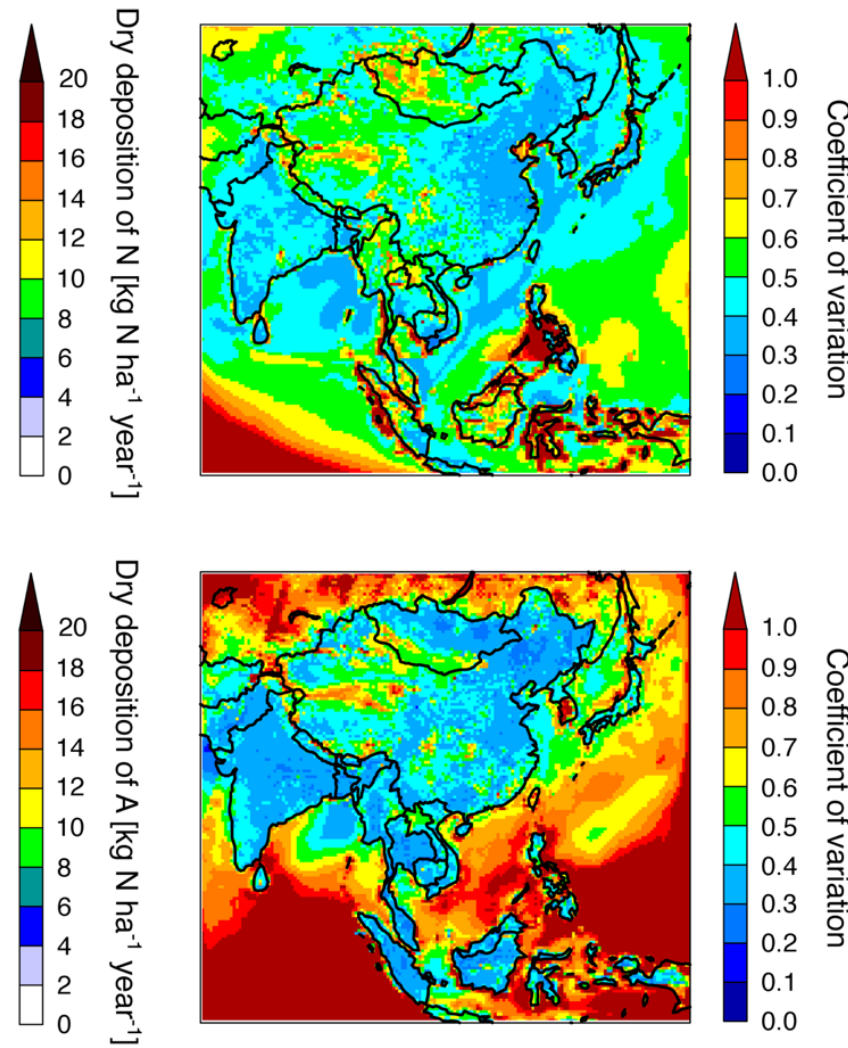

Figure S11. Spatial distributions of (left) the ensemble mean and (right) the coefficient of variation for the dry deposition of (a) S, (b) $\mathrm{N}$, and (c) A. 
(a) Total deposition of $\mathrm{S}$

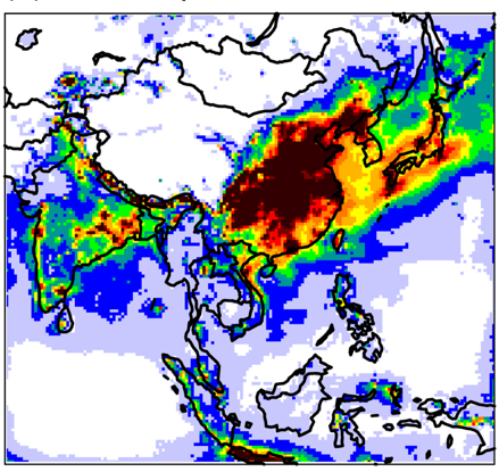

(b) Total deposition of $\mathrm{N}$

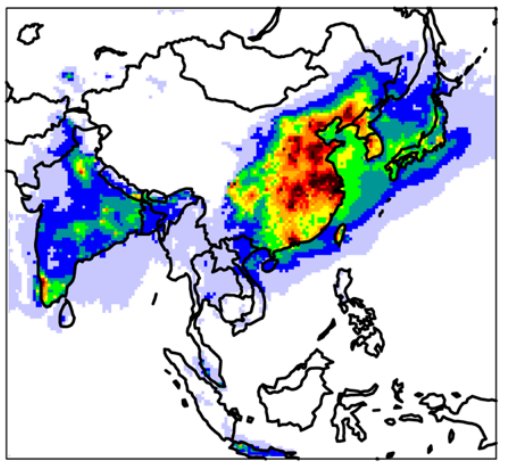

(c) Total deposition of $A$

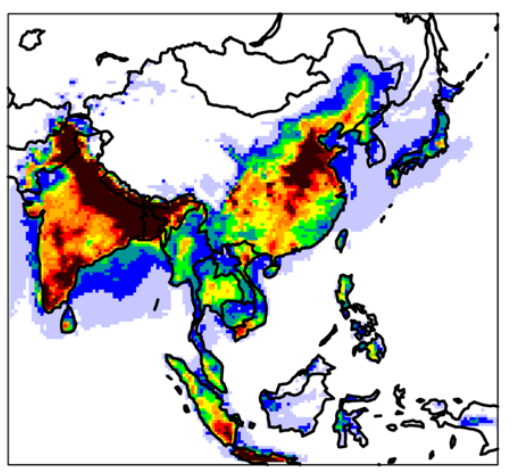

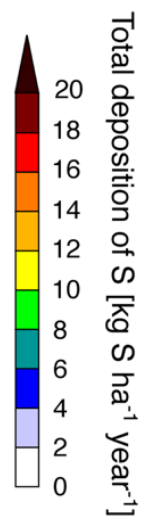
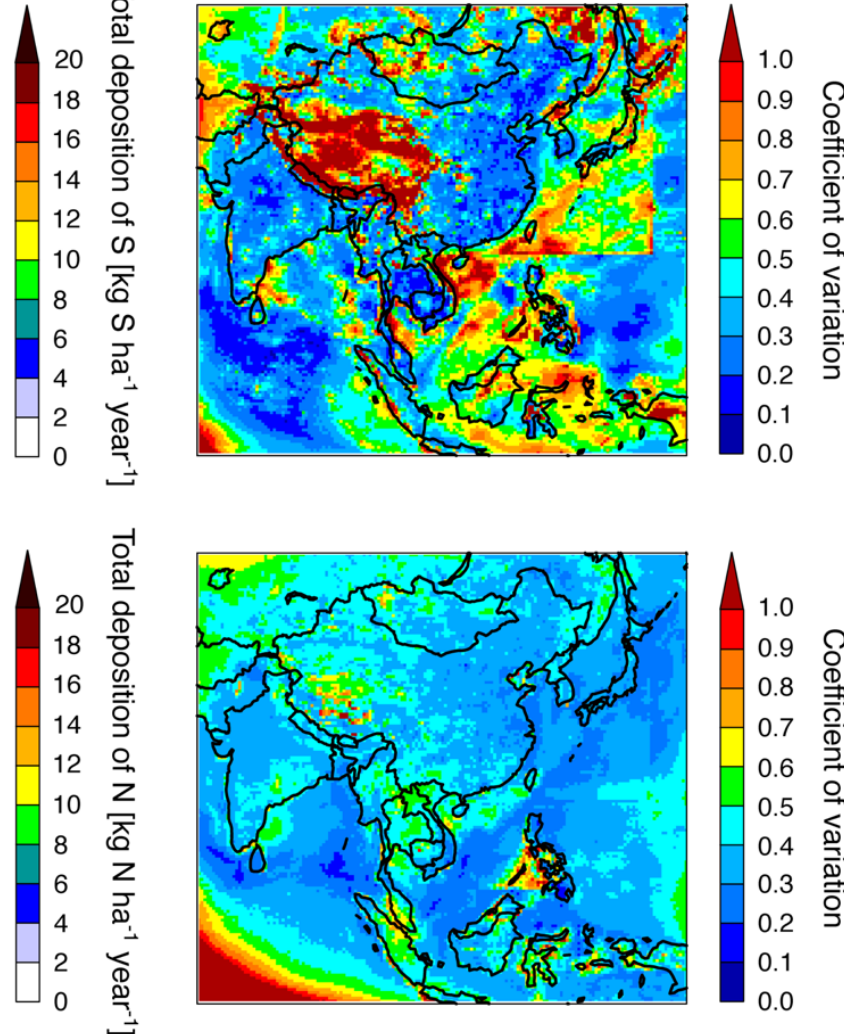

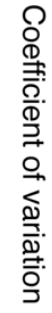

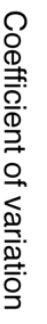

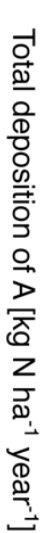

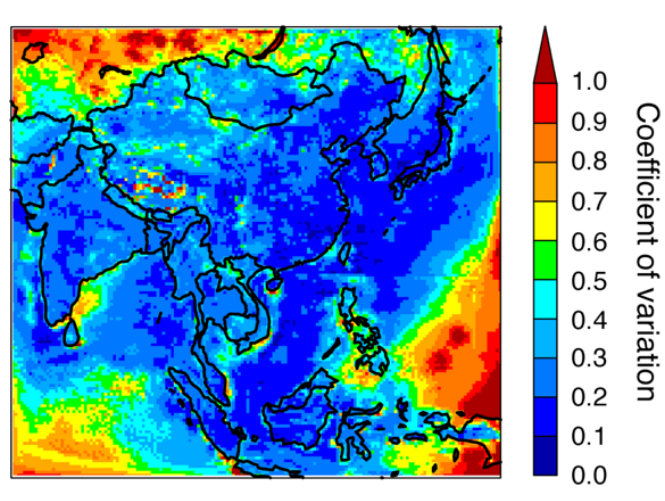

Figure S12. Spatial distributions of the ensemble mean (left) and the coefficient of variation (right) for the total deposition of (a) S, (b) $\mathrm{N}$, and (c) A. 
Table S1. Comparison of model performances for the wet deposition of S and the atmospheric concentration of $\mathrm{SO}_{4}{ }^{2-}$.

\begin{tabular}{l|l|rrrrrrrrr}
\hline \multicolumn{2}{l|}{} & \multicolumn{1}{l|}{ Model } & \multicolumn{1}{c}{ M2 } & \multicolumn{1}{c}{ M4 } & M5 & M6 & M11 & \multicolumn{1}{c}{ M12 } & M13 & M14 \\
\hline Wet & R & 0.46 & 0.38 & 0.51 & 0.54 & 0.53 & 0.50 & 0.67 & 0.34 & 0.30 \\
deposition & NMB [\%] & -39.0 & -50.4 & -36.7 & -35.2 & -32.4 & +33.8 & -13.5 & -49.2 & -58.0 \\
\hline Atmospheric & R & 0.69 & 0.71 & 0.64 & 0.58 & 0.66 & 0.55 & 0.50 & 0.76 & 0.46 \\
concentration & NMB [\%] & -23.1 & -13.0 & -31.0 & -26.4 & -26.9 & -34.5 & +23.2 & -31.9 & +69.3 \\
\hline
\end{tabular}

Note: The result of atmospheric concentration is taken from Chen et al. (2019). The analysis sites for wet deposition are the same in this work, unlike in Table 3, which used all available data.

Table S2. Comparison of model performances for the wet deposition of $\mathrm{N}$ and the atmospheric concentration of $\mathrm{NO}_{3}{ }^{-}$.

\begin{tabular}{l|l|rrrrrrrrr}
\hline Model & M1 & \multicolumn{1}{c}{ M2 } & \multicolumn{1}{c}{ M4 } & \multicolumn{1}{c}{ M5 } & \multicolumn{1}{c}{ M6 } & \multicolumn{1}{c}{ M11 } & M12 & M13 & M14 \\
\hline Wet & R & 0.35 & 0.30 & 0.34 & 0.35 & 0.32 & 0.44 & 0.33 & 0.61 & 0.50 \\
deposition & NMB [\%] & -3.7 & -56.2 & -38.3 & +14.1 & -33.5 & +37.6 & -31.1 & -32.7 & -58.9 \\
\hline Atmospheric & R & 0.55 & 0.51 & 0.62 & 0.65 & 0.58 & 0.59 & 0.60 & 0.43 & 0.58 \\
concentration & NMB [\%] & +9.0 & -7.2 & -42.7 & -1.7 & -11.8 & +46.5 & +54.0 & +22.7 & +35.4 \\
\hline
\end{tabular}

Note: The result of atmospheric concentration is taken from Chen et al. (2019). The analysis sites for wet deposition are the same in this work, unlike in Table 4, which used all available data.

Table S3. Comparison of model performances for the wet deposition of $\mathrm{A}$ and the atmospheric concentration of $\mathrm{NH}_{4}{ }^{+}$.

\begin{tabular}{l|l|rrrrrrrrrr}
\hline \multicolumn{1}{l|}{} & \multicolumn{1}{|c}{ Model } & \multicolumn{1}{c}{ M2 } & \multicolumn{1}{c}{ M4 } & M5 & \multicolumn{1}{c}{ M6 } & M11 & M12 & M13 & M14 \\
\hline Wet & R & 0.35 & 0.37 & 0.27 & 0.33 & 0.34 & 0.35 & 0.35 & 0.41 & 0.40 \\
deposition & NMB [\%] & -17.5 & -26.2 & -41.4 & -29.7 & -18.1 & -2.1 & -7.9 & +8.3 & -52.8 \\
\hline Atmospheric & R & 0.67 & 0.64 & 0.68 & 0.66 & 0.69 & 0.66 & 0.62 & 0.64 & 0.68 \\
concentration & NMB [\%] & +23.2 & +33.7 & -10.6 & +7.4 & +14.6 & +35.0 & +49.9 & +34.9 & +56.3 \\
\hline
\end{tabular}

Note: The result of atmospheric concentration is taken from Chen et al. (2019). The analysis sites for wet deposition are the same in this work, unlike in Table 5, which used all available data. 
Table S4. Composition of the dry deposition of S averaged over the domain.

\begin{tabular}{l|rrrrrrrrr}
\hline Model & \multicolumn{1}{|c}{ M1 } & \multicolumn{1}{c}{ M2 } & \multicolumn{1}{c}{ M4 } & \multicolumn{1}{c}{ M5 } & \multicolumn{1}{c}{ M6 } & M11 & M12 & M13 & M14 \\
\hline Sulfate aerosol & 31.8 & 29.4 & 19.8 & 28.2 & 26.6 & 17.9 & 14.9 & 11.7 & 50.0 \\
$\mathrm{SO}_{2}$ & 68.2 & 70.4 & 80.1 & 71.8 & 73.2 & 54.9 & 85.1 & 88.3 & 50.0 \\
$\mathrm{H}_{2} \mathrm{SO}_{4}$ & - & 0.2 & 0.2 & - & 0.2 & 27.2 & 0.1 & - & - \\
\hline
\end{tabular}

Note: Shown as a percentage of the sum of the dry deposition of S. "-_" denotes lack of data.

Table S5. Composition of the dry deposition of $\mathrm{N}$ averaged over the domain.

\begin{tabular}{l|rrrrrrrrr}
\hline Model & \multicolumn{1}{|c}{ M1 } & \multicolumn{1}{c}{ M2 } & \multicolumn{1}{c}{ M4 } & \multicolumn{1}{c}{ M5 } & \multicolumn{1}{c}{ M6 } & M11 & M12 & M13 & M14 \\
\hline Nitrate aerosol & 18.1 & 19.4 & 19.0 & 15.4 & 19.3 & 28.0 & 32.1 & 8.8 & 38.8 \\
NO & 7.1 & 0.4 & 0.6 & 0.6 & 0.3 & - & 1.4 & - & 1.6 \\
$\mathrm{NO}_{2}$ & 74.8 & 70.1 & 75.0 & 78.8 & 5.3 & - & 25.3 & 12.0 & 16.1 \\
$\mathrm{HNO}_{3}$ & 74.0 & 75.1 & 72.0 & 41.2 & 79.2 & 43.5 \\
\hline
\end{tabular}

Note: Shown as a percentage of the sum of the dry deposition of N. "-" denotes lack of data.

Table S6. Composition of the dry deposition of A averaged over the domain.

\begin{tabular}{l|rrrrrrrrr}
\hline Model & M1 & \multicolumn{1}{c}{ M2 } & M4 & M5 & M6 & M11 & M12 & M13 & M14 \\
\hline Ammonium aerosol & 13.6 & 7.3 & 11.0 & 20.3 & 10.4 & 26.6 & 13.9 & 19.9 & 18.7 \\
$\mathrm{NH}_{3}$ & 86.4 & 92.7 & 89.0 & 79.7 & 89.6 & 73.4 & 86.1 & 80.1 & 81.3 \\
\hline
\end{tabular}

Note: Shown as a percentage of the sum of the dry deposition of A. 